\title{
Influence of the crystallization temperatureon the synthesis of $Y$ zeolite
}

\author{
${ }^{1}$ Khalid Yamni, ${ }^{2}$ NajibTijani, ${ }^{3}$ Said Lamsiah \\ ${ }^{1,2,3}$ Département de chimie, Equipe Matériaux, Membranes et Procédés de SéparationFaculté des Sciences, \\ Université Moulay Ismail, Meknès, Maroc
}

\begin{abstract}
In this paper, the study of the behavior temperature of the $Y$ zeolite is discussed. In first we have synthetized the product from the two precursors of aluminate and silicate. The characterization was carried out by using X-ray diffraction powder. In the last step of the synthesis, we have chosen the crystallization temperature. The obtention of the $Y$ zeolite is mostly affected by this parameter. In order to follow the effect of this, 3 values are chosen for this synthesis. The 3 powders were characterized by XRD. The obtained spectrawere decomposed and indexed to obtain the Laue group space. The research of the best space group is undertaken in CheckCell program.

The analysis of the different solution with different CFOM allowed the choice of the true solution. To validate the result, profile matching with Fullprof program is made. This transition let us think that the evolution from cubic to tetragonal systems can be explained by the relation group-subgroup.
\end{abstract}

Keywords: Y zeolite, Crystallization Temperature, XRD, Fullprof, CheckCell

\section{Introduction}

Zeolites are porous crystalline aluminosilicates. The zeolite materials were introduced by Cronstedt who discovered in 1756 [1]; they play an important role in many areas (petrochemical, pharmaceutical, adsorption etc.) $[2,3,4]$. In the present work we opted to synthesize a Y zeolite with a variable crystallization temperature program $\left(60^{\circ} \mathrm{C}, 80^{\circ} \mathrm{C}\right.$ and $\left.100^{\circ} \mathrm{C}\right)$. The temperature is a very important factor, which affects a manner different zeolite synthesis[5].It can control (increase or decrease) the rate of crystallization, but also the type of zeolite formed. Generally high synthesis temperatures lead to the formation of dense phases. The Characterization by XRD showed that the zeolite Y (pure) corresponds to samples which have undergone a crystallization temperature in $60^{\circ} \mathrm{C}$. when the crystallization temperature is closed to $100^{\circ} \mathrm{C}$; we have seen the formation of another phase matching zeolite $\mathrm{P}$.

\section{Experimental}

The synthesis [6] procedure is divided into two stages:

- Preparation of germination and the growth gel.

- Mixture of the precursors previously prepared.

The germination gel is prepared by the following method:in first NaOHand aluminate ( $\mathrm{NaAlO} 2$ $0.0065 \mathrm{~mol}$ ) of sodium are dissolved in distilled water. After the solution of sodium silicate ( $\mathrm{Na} 2 \mathrm{Si} 3 \mathrm{O} 70.023$ $\mathrm{mol}$ ) are added to the aluminate precursor. The obtained mixture is aging for $24 \mathrm{~h}$ at room temperature under stirring.

The growth gel is prepared by the following manner:NaOHand of aluminate ( $\mathrm{NaAlO} 20.04 \mathrm{~mol}$ ) of sodium are dissolved in distilled water. Thesolution of sodium silicate $(0.147 \mathrm{~mol} \mathrm{Na} 2 \mathrm{Si} 3 \mathrm{O} 7)$ areaddedvery slowly on the aluminate precursorunder vigorous stirring. The gel is made to mature for two hours after the end of addition. Then germination gel is added on the growth gel under vigorous stirring and the whole is placed in an oven at $\left(120^{\circ} \mathrm{C}, 100^{\circ} \mathrm{C}, 80^{\circ} \mathrm{C}, 60^{\circ} \mathrm{C}\right)$ for 24 hours in a closed polyethylene container. After the zeolite is filtered and washed with distilled water on a Buchner funnel until the $\mathrm{pH} 10$ and finally dried in an oven at 100 ${ }^{\circ} \mathrm{C}$ for $12 \mathrm{H}$.

\section{Characterization of the $\mathrm{Y}$ zeolites sample by $\mathrm{X}$-ray diffraction}

X-ray powder diffraction data were collected with a 6100 Shimadzu diffractometer using $\mathrm{CuK} \alpha$ radiation and a monochromator. The measured 2 theta range $\left(5-90^{\circ}\right)$ was scanned in steps of $0.02^{\circ}$ with a counting time of 3s/step. This 2 theta range was used for the refinement of cell parameter. The aperture and the soller slits were set at $1.0^{\circ}$.

The geometry is the $\theta-2 \theta$. The sample is ground.

In order to follow the effect of the crystallization temperatureon thesynthesis of $\mathrm{Y}$ zeolite, we have elaborated three zeolites at different temperatures. All others parameters of the synthesis are the same.The first elaborated product are the $\mathrm{Y}$ zeolite at $80^{\circ} \mathrm{C}$ figure 1 . 


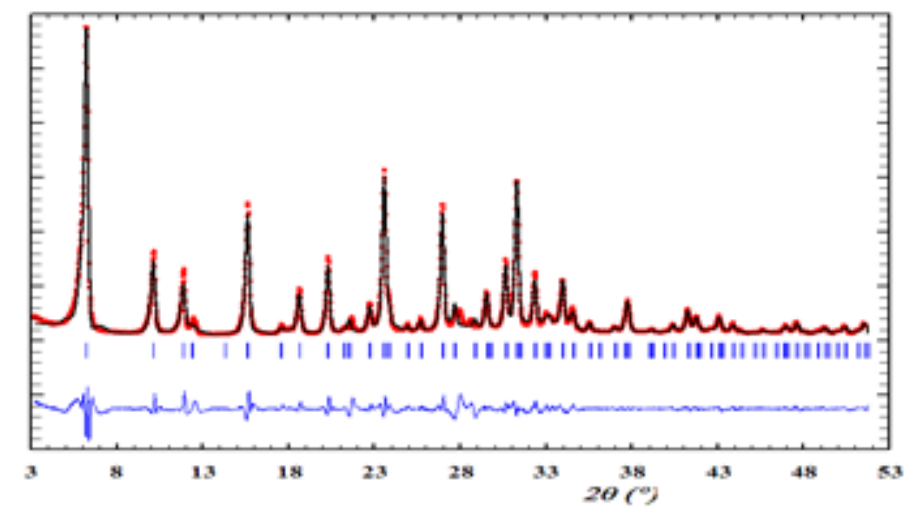

Figure 1: $\mathrm{x}$ ray spectrum of the $\mathrm{Y}$ zeolite at $80^{\circ} \mathrm{C}$

The decomposition of the spectra and the indexation were made by DicVolprogram [7]. The table 1summarizes the result given by this software.

Table 1: parameters of cellby DicVol program

\begin{tabular}{|l|c|c|c|c|c|c|c|}
\hline & $\mathbf{a}(\AA)$ & $\mathbf{b}(\AA)$ & $\mathbf{c}(\AA)$ & Alpha & beta & gamma & Space group \\
\hline $\begin{array}{l}\text { Y zeolite } \\
\mathbf{8 0}\end{array}$ & 24.7974 & 24.7974 & 24.7974 & 90.000 & 90.000 & 90.000 & $\mathrm{P} \mathrm{m}-3 \mathrm{~m}$ \\
\hline
\end{tabular}

The space group is the holoeder $\mathrm{P} \mathrm{m} 3 \mathrm{~m}$. Thesearchof the best space groupwas done by two programs ChekCell and CheckGroup [8]. The result is Fd-3m. To fit the spectrum, we use Fullprof program [9] with Pseudo Voigt as function of profile. We can note on the spectra in figure 2 the existence of some satellitespeaksnot fitted by this space group. That let usthink that process of crystallization is probably in evolution.

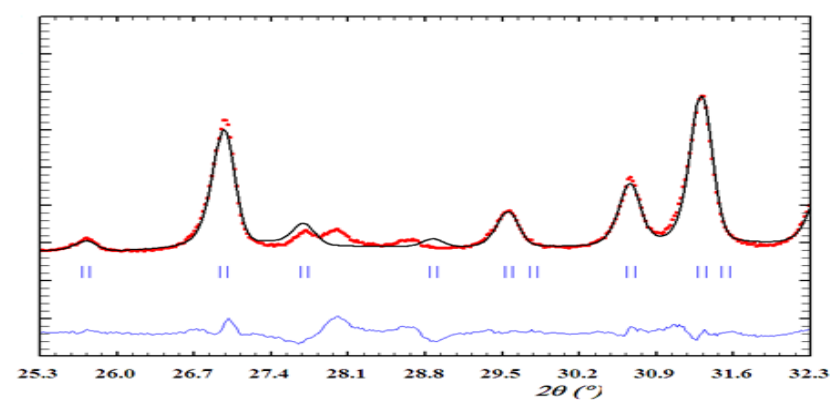

Figure 2: some satellites peaks not fitted by profile function

So we have decided to synthesizetwo $\mathrm{Y}$ zeolitesat lower and higher temperaturesthan $80^{\circ} \mathrm{C}$. When we recorded anX ray spectrum of the $\mathrm{Y}$ zeolite at $60^{\circ} \mathrm{C}$, we note the absence of the satellitespeaks. And the spectrum of this $\mathrm{Y}$ zeolite is pure. The figure 3 shows the obtained spectrum.

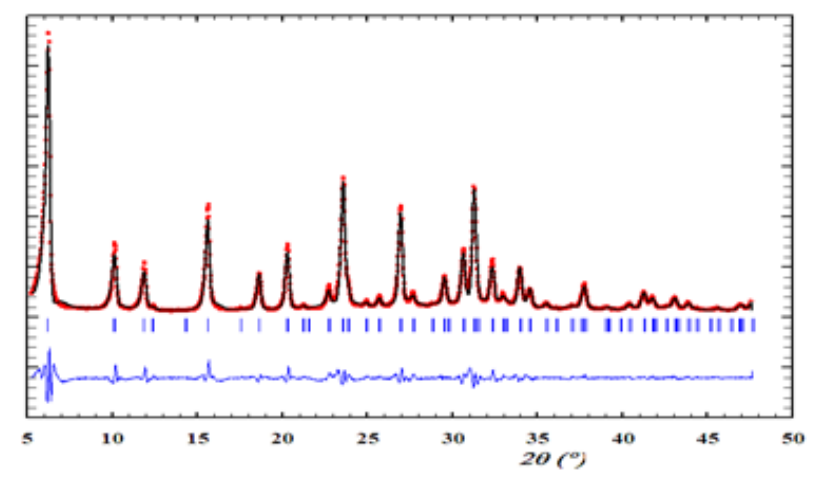

Figure 3: $\mathrm{x}$ ray pattern of the $\mathrm{Y}$ zeolite at $60^{\circ} \mathrm{C}$

Also we present in the figure 4 the region that clearly shows the absence of the satellite peaks. 


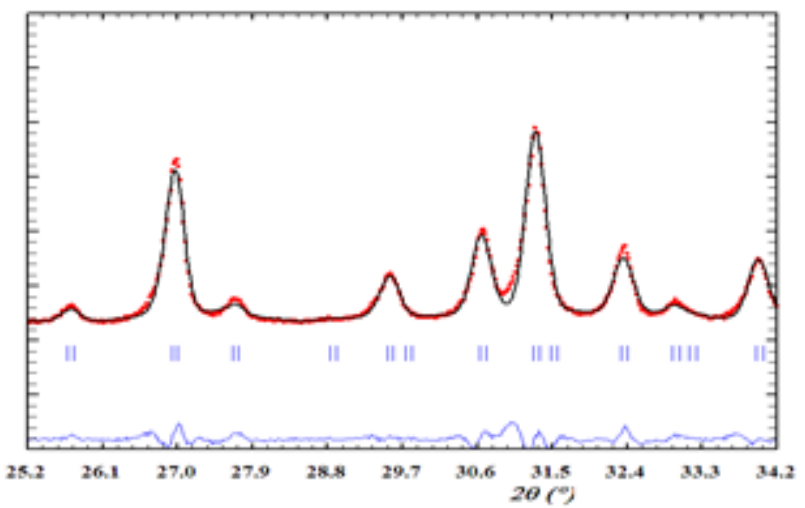

Figure 4: absence of satellites peaks in the $\mathrm{Y}$ zeolite elaborated at $60^{\circ} \mathrm{C}$

The Y zeolite elaborated at $100^{\circ} \mathrm{C}$ shows a change of crystal system. It becomes a $\mathrm{P}$ zeolite and crystallizes in the tetragonal crystal system. The table 2 below gives the metric of the lattice. The profile matching applied on the data gives the refinement parameters below.

Table 2: parameters of lattice of the $\mathrm{P}$ zeolite elaborated at $100^{\circ} \mathrm{C}$

\begin{tabular}{|l|c|c|c|c|c|c|}
\hline & $\mathbf{a}(\AA)$ & $\mathbf{b}(\AA)$ & $\mathbf{c}(\AA)$ & Alpha & beta & gamma \\
\hline P zeolite & 9.9958 & 9.9958 & 10.0184 & 90 & 90 & 120 \\
\hline
\end{tabular}

With the CheckCell program, we find the space group I-4. The figure 5 shows the refinement obtained by profile matching.

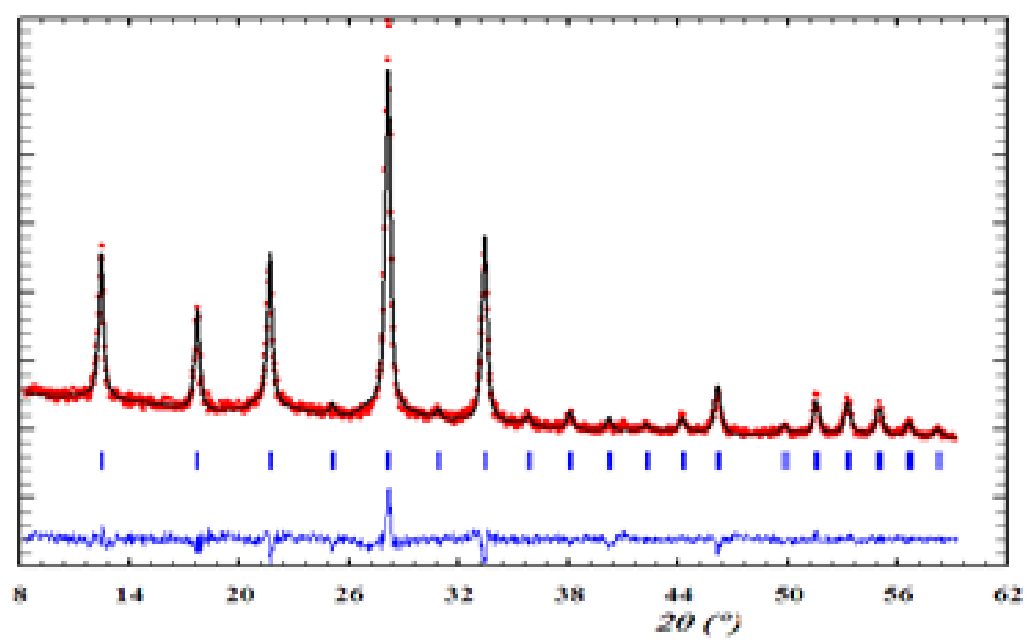

Figure 5: $\mathrm{X}$ ray spectrum of the $\mathrm{Y}$ zeolite elaborated at $100^{\circ} \mathrm{C}$

\section{Conclusion}

The synthesis of the Y zeolite is mostly affected by the crystallization temperature. In this work, the transformation is followed by $\mathrm{X}$ ray diffraction on the elaborated powders. The apparition of some peaks in the $2 \Theta r$ region $25^{\circ}-30^{\circ}$ is a great sign for modification of the structure of the $\mathrm{Y}$ zeolite. The synthesis at lower and higher temperature than $80^{\circ} \mathrm{Cgives}$ the Yand the $\mathrm{P}$ zeolites respectively. The behavior of the $\mathrm{Y}$ zeolite versus crystallization temperature can be explained by the relation between group subgroup[10]. The figure 6 below resumes this relation: 


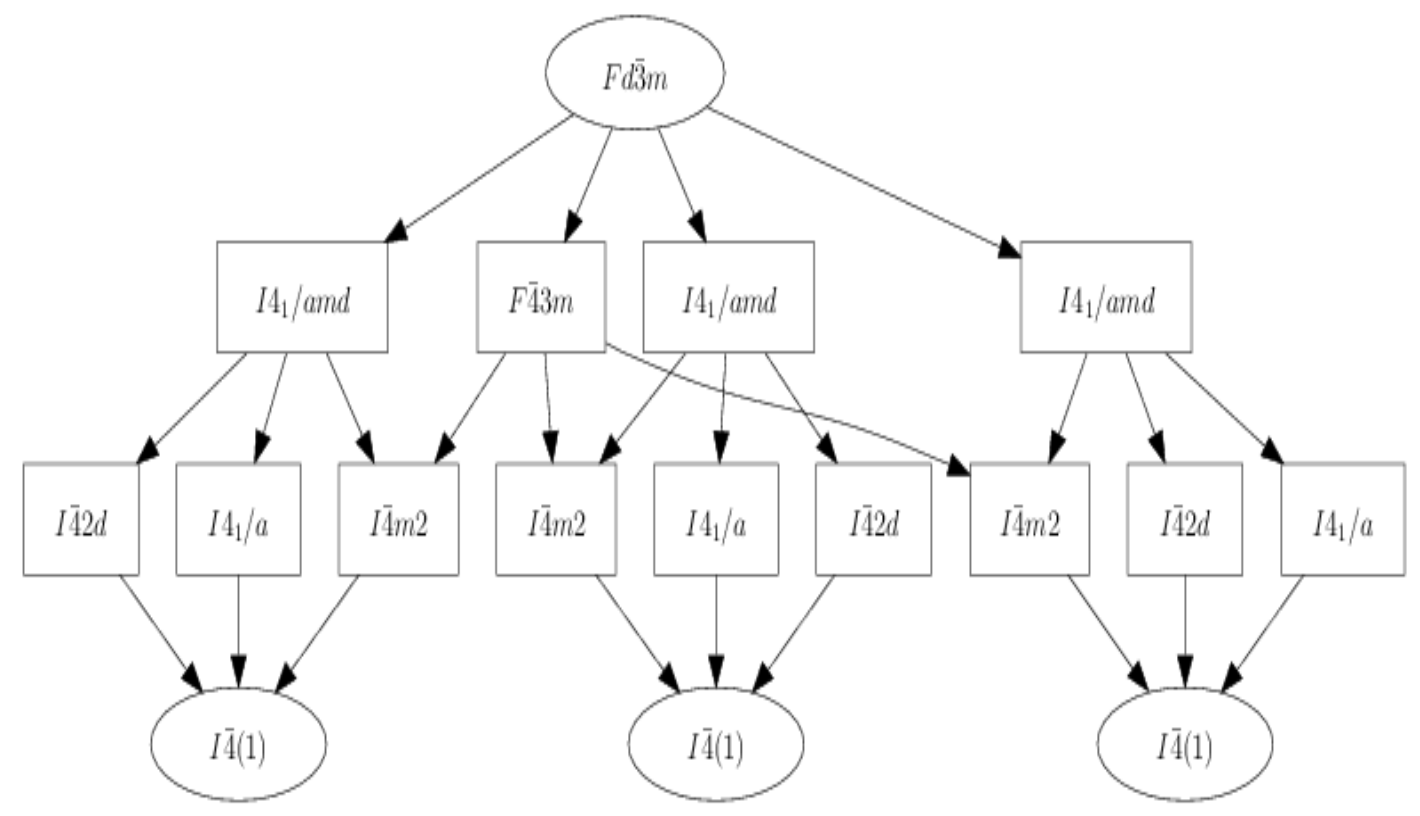

Figure 6: relation group subgroup between Fd-3m and I-4

The transformation between group subgroup and theexplanation ofthe splitting Wyckoffpositionsof this transition are understudy.

\section{References}

[1] A. F. Cronstedt, Natural Zeolite and Minerals, Acad. Handl. Stockholm 17, 120 (1756).

[2] BA Hobmberg, HT Wang, JM Norbeck etal.MicroporeuxMesoporous Mater., 59 (2003), p.13

[3] B. Wang, HZ Ma MicroporeuxMesoporous Mater., 25 (1998), p. 131

[4] NajibTijani, Khalid Yamni, Said Lamsiah and Abdelhadi El Krouk(IOSR-JESTFT).Volume 8, Issue 5 Ver. IV (May. 2014), pp 9093

[5 ] Shiun Sang, Zhongmin, Pen Tian; Ziyu Liu and Yangyang Zhang Synthesisofsmallcrystals zeolite NaY Materials Lettre 60 (2006) $1131-1133$

[6] N. Tijani, H. Ahlafi, M. El SMAIHI, a.elmansouri, Preparation and characterization of NaA Zeolite membranes and its application for removal of heavy metals Mediteranen journal of chemistry 2013, 2(3), 484-492

[7] DicVol by D. Louer and A. Boultif

[8] CHECKCELL program, Ed 2004, Jean Laugier et Bernard Bochu

[9] FULLPROF SUITE program, Ed 2012, J R Carvajal

[10] http://www.cryst.ehu.es/ 